\title{
Ocorrência de mancha aureolada em cafeeiros na Região do Triângulo Mineiro e Alto Paranaíba
}

\author{
Débora Maria Zoccoli ( $\left.{ }^{1 *}\right)$; Armando Takatsu (2); Carlos Hidemi Uesugi ( $\left.{ }^{2}\right)$ \\ (') HATTEN, Tecnologia de Produção Sustentável Ltda. 70673-409 Brasília (DF), Brasil. \\ (2) Universidade de Brasília, Instituto de Ciências Biológicas, Bloco C, Asa Norte, 70910-900 Brasília (DF), Brasil. \\ (*) Autora correspondente: deborazoccoli@yahoo.com.br
}

Recebido: 22/out./2010; Aceito: 1.\%abr./2011.

\begin{abstract}
Resumo
A mancha aureolada do cafeeiro, causada por Pseudomonas syringae pv. garcae, pode provocar perdas de até $70 \%$ em viveiros e campos estabelecidos em regiões sujeitas a ventos fortes, temperaturas amenas, chuvas frequentes e bem distribuídas. Por meio de levantamento foi detectada a incidência frequente da mancha aureolada com severidade variável, alternando-se ao longo dos anos nas áreas serranas do Triângulo Mineiro e Alto Paranaíba, de topografia acidentada e altitudes superiores a 1000 metros, constituindo-se em sério problema, que pode inviabilizar o cultivo do cafeeiro naquelas áreas, devido à ameaça pela doença. Foi estabelecida uma zona bastante nítida quanto às condições favoráveis para ocorrência da mancha aureolada compreendendo os municípios de Serra do Salitre, Carmo do Paranaíba, Rio Paranaíba, São Gotardo e Tiros. Foi possível recuperar P. S. pv. garcae e P. cichorii de folhas sadias em diferentes estádios de desenvolvimento da planta, desde mudas até cafezais adultos e plenamente estabelecidos. A recuperação foi realizada pelo método de fricção da folha em meio de cultura semisseletivo, na ausência de sintomas, demonstrando a possibilidade de detecção da bactéria em plantas sadias. Dentre as variedades solicitadas pelos produtores para plantio em 2003/2004, não há nenhum material resistente, podendo, portanto, perdurar os focos de epidemias.
\end{abstract}

Palavras-chave: mancha aureolada, epidemiologia, resistência genética, Coffea arabica.

\section{Occurrence of halo bright in coffee trees in Triângulo Mineiro and Alto Paranaíba Region's, Brazil}

\section{Abstract}

Pseudomonas syringae pv. garcae causes the disease known as halo blight of the coffee tree. It can cause up to $70 \%$ losses in nurseries and fields established in regions under strong winds, mild temperatures, frequent and well distributed rains. The survey detected the frequent incidence of the halo blight with variable severity, alternating through the years in the mountainous areas of the "Triângulo Mineiro" and "Alto Paranaíba" with irregular topography and altitudes over the 1000 meters. It is a serious problem, which may limit the coffee cultivation due to threat of the disease. A clear zone with favorable conditions for occurrence of the halo blight was defined. It is composed by the counties of Serra do Salitre, Carmo do Paranaíba, Rio Paranaíba, São Gotardo and Tiros. The bacteria P. s. pv. garcae and P. cichorii were recovered from healthy leaves of coffee trees, in both seedlings and mature trees. The recovery was conducted using the friction of the leaves in selective culture media in the absence of symptoms, demonstrating the possibility of detecting the pathogen in healthy plants. Among the varieties requested by the producers to be used in 2003/2004, there are no available resistant varieties, which is unfavorable for disease management.

Key words: halo blight, epidemiology, genetic resistance, Coffea Arabica. 


\section{INTRODUÇÃO}

A mancha aureolada do cafeeiro (Coffea arabica L.), causada por Pseudomonas syringae pv. garcae (Psg) é uma bacteriose comum na regiâo do Alto Paranaíba (MG) sendo os primeiros relatos da década de 1980 em São Gotardo, em épocas chuvosas, provocando intensa seca de ramos (VAlE e Zambolim, 1997). Possui esta denominação em decorrência da formaçáo de um halo amarelo circundando as lesóes (Carvalho e Chaulfoun, 2000). É conhecida também como crestamento bacteriano ou mancha bacteriana.

Descrita no Brasil pela primeira vez no município de Garça, Estado de São Paulo (Amaral et al., 1956), a doença incide sobre folhas, rosetas, frutos novos e ramos do cafeeiro, atingindo mudas em viveiros e plantas mais novas no campo. A doença incide em folhas, frutos novos e extremidades de ramos em crescimento. Nas folhas mais velhas, os sintomas consistem em manchas de conformação irregular, de coloração pardo-escura, envolvidas por anel amarelo, característico da doença. Em folhas novas, o anel amarelo nas lesôes circulares pode não ser notado, mas é possível perceber uma transparência desta região observando as folhas atacadas contra a luz. No viveiro, a doença provoca queima das folhas e necrose dos tecidos jovens (ZамвоLim et al., 1999; 2005).

Segundo SERA (2001), a mancha aureolada tem-se tornado limitante em regióes mais frias, em face exposta ao vento, sendo nestas condiçóes considerada uma das principais doenças dos cafezais. Esse problema torna-se preocupante pela ausência de medidas adequadas de controle que leva a perdas econômicas e ao aumento no custo de produção devido ao acréscimo de aplicaçôes de bactericidas e fungicidas na tentativa de conter o avanço da doença em regióes mais favoráveis à sua incidência.

A falta de informaçóes sobre a dinâmica desta doença, a ausência de produtos específicos registrados e o desenvolvimento de resistência do patógeno a antibióticos têm dificultado o controle da doença (Jesus Junior et al., 2002). Patrício et al. (2002) verificaram que cloridrato de kazugamicina $(300 \mathrm{~mL} / 100 \mathrm{~L}$ de água) e oxicloreto de cobre reduziram a incidência de mancha aureolada e acibenzolar-s-methyl (BTH), indutor de resistência, resultou em proteção nas doses de 20 e $40 \mathrm{~g}$.

Segundo Godoy et al. (1997), um fato é claramente reconhecido quanto à necessidade de prevenção por meio de medidas como a instalaçấo de quebra-ventos na fase de formação do cafezal. Compostos cúpricos vêm sendo utilizados no controle de doenças bacterianas devido à sua relativa eficácia, ao baixo custo e baixo efeito tóxico em mamíferos, o que os torna econômica e ecologicamente adequados (CHA e CoоKsey, 1991 apud Araujo et al., 2003).

Esta situação sem medidas de controle bem definidas deixam os produtores apoiados somente em suas próprias experiências, e sendo obrigados a renovar precocemente o cafezal em razão das perdas irrecuperáveis, acentuando assim os riscos já inerentes à atividade em decorrência da doença.

O presente trabalho teve como objetivos realizar um levantamento em relação à ocorrência da mancha aureolada nos municípios que se destacam na produção de café do Triângulo Mineiro e Alto Paranaíba, relacionando condições meteorológicas com a predisposição à doença; verificar a possibilidade de detecção da bactéria $P s g$ em folhas de cafeeiro, em diferentes fases fenológicas, na ausência de sintomas, para previsão de controle; avaliar o comportamento de algumas cultivares de café que foram solicitadas na região para plantio em 2003/2004, em relação à mancha aureolada e certificar se as atuais epidemias se devem ou não à ocorrência de formas pouco sensíveis aos fungicidas cúpricos muito utilizados na cafeicultura através da avaliação do nível de sensibilidade de isolados de Psg ao cobre.

\section{MATERIAL E MÉTODOS}

\section{Levantamento da ocorrência da mancha aureolada na região do Triângulo Mineiro e Alto Paranaíba}

O procedimento inicial foi enviar questionários aos produtores, cooperativas, associaçóes de produtores e empresas de extensão rural (Empresa de Assistência Técnica e Extensão Rural - EMATER), de pesquisa ligada à cafeicultura (Empresa de Pesquisa Agropecuária Mineira EPAMIG) e de revenda de insumos agrícolas, durante o período de 2000 até 2004 , após a primeira constatação da doença em Patrocínio. Foram anexadas ilustrações dos sintomas da bacteriose aos questionários, que visavam identificar os municípios que se destacavam na ocorrência dos prováveis eventos epidemiológicos da doença, os prováveis danos pela mancha aureolada e a necessidade de realizar controle específico.

Foram realizadas visitas técnicas aos viveiros e às lavouras de café das diversas cidades onde declararam a existência de focos da bacteriose, procedendo à coleta de material vegetal com suspeita de infecçáo bacteriana. Procedeu-se a coleta de material e confirmação da associação do sintoma existente, ao patógeno estudado $\left(P_{s g} g\right.$ ) por meio da diagnose em laboratório.

\section{Análise das condições meteorológicas favoráveis à mancha aureolada}

Para análise das condiçốes favoráveis a ocorrência da doença, relacionando o período de incidência observado no campo, procurou-se avaliar os dados climatológicos dos principais municípios produtores de café obtidos no INMET (Instituto Nacional de Meteorologia). Os dados 
disponíveis avaliados foram mensais e anuais de temperaturas (médias, médias das máximas, médias das mínimas, extremas máximas e extremas mínimas), umidade relativa (médias, máximas e mínimas) e de precipitação pluvial (total máximo em 24 horas e dias de chuva). As análises foram feitas em função da fase fenológica do cafeeiro e não do curso anual regular.

Detecção de Pseudomonas syringae pv. garcae no filoplano do cafeeiro, na ausência de sintomas

Para possibilitar a recuperação de $P s g$ a partir da superfície foliar em um meio de cultura favorável ao desenvolvimento desta bactéria e desfavorável a outros microrganismos, foram executados testes com os seguintes componentes: ácido bórico, cefalexina, ampicilina e tiofanato metílico + chlorothalonil, usando-se como meios básicos o meio 523 (Kado e Heskett, 1970) ou King B (King et al., 1954).

A composição final do meio foi definida como: caseína hidrolisada ácida $(10 \mathrm{~g})$; glicerina $(15 \mathrm{ml})$; sulfato de magnésio $(0,30 \mathrm{~g})$; clara de um ovo médio; ácido bórico (1 g); cefalexina (75 mg); Cerconil - mistura de chlorotalonil + tiofanato metílico (200 mg) e água destilada para completar 1 litro.

Culturas puras previamente identificadas de Psg foram diluídas em série em água e plaqueadas neste meio para visualizar as características culturais e possibilitar a identificação visual das colônias isoladas neste meio de cultura.

O método utilizado na recuperação de $P s g$ do filoplano teve como princípio friccionar folhas de cafeeiro assintomáticas sobre a superfície do meio de cultura semisseletivo, executando em placas diferentes a fricção da superfície superior e a inferior da mesma folha.

A coleta de folhas foi realizada durante as visitas técnicas nas lavouras que compuseram as áreas do experimento, notando-se as seguintes características na ocasião da coleta: no município de Patos de Minas, a doença não havia se manifestado na época da realização do experimento, tendo sido considerado o tratamento-controle; em Rio Paranaíba, as plantas do cafezal com sintomas típicos tinham sido tratadas com hipoclorito de sódio, e em Tiros, as mudas com sintomas da bacteriose tinham sido tratadas com hipoclorito de sódio e as plantas dos cafezais adultos com Agrimicina; havia áreas onde não se aplicou de nenhum produto químico, e não ocorreram sintomas de mancha aureolada.

Após a coleta das folhas sadias, estas eram friccionadas imediatamente sobre o meio de cultura previamente preparado. Para cada tratamento (característica da área e face foliar) foram realizadas três repetições. As placas foram acondicionadas em sacos plásticos até serem conduzidas para o laboratório para incubação. Diariamente, as placas eram examinadas até o quarto dia de incubação a $28^{\circ} \mathrm{C}$ quando se procedeu a contagem das colônias cujas características morfológicas indicavam ser Psg. Após a contagem, as colônias foram repicadas em meio 523 para obtenção de cultura pura e posterior realização dos testes bioquímicos para consolidação da identificação.

\section{Teste para avaliação de resistência à mancha aureolada em cultivares de cafeeiro}

Foram avaliadas cultivares de cafeeiro visando identificar resistência à mancha aureolada, dentre as variedades mais solicitadas para plantio em 2004, nas regiôes de Patrocínio e Monte Carmelo, ou seja: Catuaí Vermelho 51 (CV 51); Catuaí 99; Acaiá Cerrado; IAPAR 59; Mundo Novo (MN) e Topázio. As mudas foram obtidas de viveiros especializados e estavam na idade recomendada para plantio.

As mudas foram submetidas à inoculaçáo com um isolado de Psg, proveniente de Carmo do Paranaíba, o qual demonstrou maior agressividade no teste de patogenicidade.

A inoculação das mudas de café foi realizada pelo método de puntuação com multiagulhas, tendo sido confeccionadas manualmente um conjunto de agulhas (aproximadamente 12) fixadas em uma superfície resistente. As agulhas previamente imersas na suspensão bacteriana de concentração $1 \times 10^{8} \mathrm{UFCmL}^{-1}$ foram perfuradas, considerando do ápice para a base da planta, nos pares de folhas jovens e desenvolvidas, bem como nos folíolos que estavam iniciando o desenvolvimento, e no par de folhas logo abaixo desta folha mais jovem plenamente desenvolvida, considerada folha adulta.

Para cada variedade, foram submetidas à inoculação 27 mudas e distribuídas em delineamento inteiramente casualizado. Este experimento foi realizado em casa de vegetação. Após a inoculação, as plantas permaneceram por 48 horas em câmara úmida. Nos dias subsequentes, efetuaram-se, em média, duas irrigaçóes diárias até o décimo quinto dia após a inoculação, quando ocorreu a avaliação.

O critério de avaliação considerado foi a presença ou não de sintomas e a evolução conforme a escala diagramática elaborada, atribuindo notas de 1 a 5 à severidade da doença conforme mostra a figura 1 . Consideraram-se

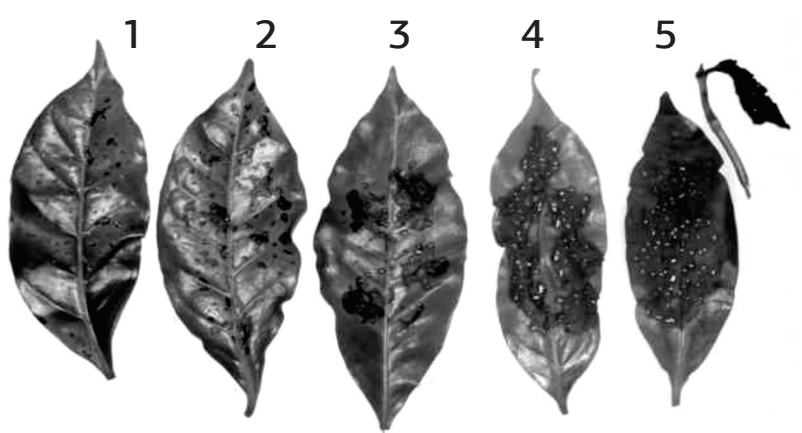

Figura 1. Escala de notas para avaliaçáo da mancha aureolada do cafeeiro. 
separadamente os sintomas em folhas novas (folha jovem e ponteiro) e folhas velhas (par subsequente de folhas plenamente desenvolvida).

\section{Sensibilidade dos isolados de Psg ao cobre}

Foram utilizados para esse teste seis isolados de $P s g$ provenientes de lavouras localizadas nos municípios de Carmo do Paranaíba, Patrocínio, Patos de Minas e Patrocínio.

O meio de cultura para o teste de sensibilidade ao cobre tinha a seguinte composição: $3 \mathrm{~g}$ de caseína hidrolisada; 0,6 $\mathrm{g}$ de extrato de levedura; $3 \mathrm{ml}$ de glicerina e $18 \mathrm{~g}$ de ágar bacteriológico para um volume final de 1,5 litro de água destilada. $\mathrm{O}$ pH foi ajustado para 7. Previamente, preparou-se uma soluçáo-estoque com $10 \%$ de sulfato de cobre $\left(\mathrm{CuSO}_{4} \times 5 \mathrm{H}_{2} \mathrm{O}\right)$ deixando esta reservada, mas agitando periodicamente até dissolver todo conteúdo. Ao meio de cultura citado com aproximadamente $50^{\circ} \mathrm{C}$ foi adicionado a solução de sulfato de cobre, a fim de obter meio com cobre nas concentraçóes de 50, 100, 200, 300, 500, 1000 ppm. A testemunha foi o mesmo meio sem cobre na composição.

Os isolados de Psg foram plaqueados nos meios com cobre, adicionando-se $0,5 \mathrm{~mL}$ da suspensão bacteriana na concentração de $1 \times 10^{8} \mathrm{ufc} \mathrm{mL}^{-1}$, em quatro repetiçôes.

A avaliação ocorreu após três dias de incubação a $28^{\circ} \mathrm{C}$, observando-se o crescimento bacteriano positivo (crescimento bacteriano) ou negativo (ausência de crescimento).

\section{RESULTADOS E DISCUSSÃO}

O levantamento sobre a ocorrência da mancha aureolada em cafeeiros na Região do Triângulo Mineiro e Alto Paranaíba permitiu o estabelecimento de uma zona bastante nítida quanto às condiçóes favoráveis para incidência e severidade da mancha aureolada dentre as regióes que compuseram o diagnóstico. A maioria dos dados qualitativos obtidos pelos questionários sobre a ocorrência da mancha aureolada e confirmaçóes durante as visitas técnicas foram provenientes das áreas mais montanhosas. Essas são consideradas como as regióes mais favoráveis, de altitude acima de $1000 \mathrm{~m}$, onde existem culturas estabelecidas sobre platôs ou terrenos com declividade acentuada, exposta a ventos fortes e/ou constantes e também às geadas esporádicas fracas no inverno. Estas áreas compreendem os municípios de Serra do Salitre (altitude de 1203 m), Carmo do Paranaíba (1061 m), Rio Paranaíba (1148 m), São Gotardo (1100 m), Tiros (1037 m), e também os municípios que possuem algumas áreas de cultivo situadas em locais superiores a $1000 \mathrm{~m}$ de altitude, como Patrocínio, Patos de Minas e Presidente Olegário.

Nessas regiōes, segundo as respostas aos questionários, a doença não é de ocorrência recente, e tem sido frequente nos últimos anos, variando em severidade. Os produtores consideram a mancha aureolada como uma das doenças mais importantes do cafeeiro e muito preocupante por não dispor de medidas adequadas para controle. Atribuem à alta severidade, a alta pluviosidade (média anual de $\pm 1450 \mathrm{~mm}$ ) e predominância de ventos fortes e também a ocorrência de chuvas de granizo, que são relativamente frequentes, especialmente no início do período das chuvas, quando os tecidos estão tenros.

Nas áreas produtoras de café cuja altitude se situa abaixo dos $1000 \mathrm{~m}$, compreendendo os municípios de Araguari, Romaria, Monte Carmelo, Coromandel e adjacentes, as respostas aos questionários eram, na grande maioria, negativas quanto à ocorrência da mancha aureolada. Ocorrências esporádicas foram relatadas pelos técnicos de extensão rural e de assistência técnica, mas não a consideram como doença preocupante.

A validade das respostas aos questionários enviados, especialmente em relação à ocorrência ou não da doença, pode ser confirmada pela visita posterior às localidades representativas para análise in loco, coleta de materiais e comprovação através de testes de laboratório. Com a junção destes recursos, o envio de questionários foi um método de trabalho considerado válido para o estudo desta doença e extremamente útil na localização rápida dos locais onde há a predominância desta doença resultando em economia de tempo e de recursos.

As informaçôes obtidas neste trabalho concordam em grande parte aos aspectos epidemiológicos da doença constantes na literatura (CARvalho e Chalfoun, 2000; Godoy et al., 1997; Ferreira e Salgado, 1997; ZамвоLim et al., 1997), exceto quanto ao período de julho a setembro em que praticamente não há manifestação de sintomas por ser um período muito seco, sem precipitação pluvial nesta região dos cerrados. As características dos meses de agosto e setembro na região dos cerrados se diferenciam ainda das demais regiôes produtoras de café, por ser um período mais quente do ano, totalmente desfavorável à mancha aureolada.

Pela análise comparativa dos dados climatológicos disponíveis, os quais incluem temperaturas mensais e anuais (médias gerais, médias das máximas e das mínimas, extremas das máximas e mínimas), umidades relativas (médias, máximas e mínimas) e de precipitaçôes pluviais (médias anuais e mensais, total máxima em 24 horas e dias de chuva mensais), pode-se concluir que estes dados são insuficientes para definir os parâmetros climatológicos que diferenciam as regiōes favoráveis (por exemplo a região de Carmo de Paranaíba, com altitude um pouco acima de 1000 m) e desfavoráveis (a de Araguari, com 950 m) para a ocorrência, persistência e severidade da mancha aureolada. A definição destes parâmetros é fundamental para se determinar as estratégias mais adequadas de controle integrado. Serão necessários dados climatológicos mais refinados tais como a faixa de temperatura em que as folhas são mais suscetíveis, o tempo de duração do molhamento 
foliar para haver a infecção, assim como a velocidade e a duração do vento e o impacto das chuvas.

Conforme demonstrado na figura 2 e segundo relatos prévios de Hirano e Upper (1983), é possível recuperar a bactéria $P_{s g}$ através de folhas sadias desde mudas até cafezais adultos e plenamente estabelecidos. Hirano e Upper (1983) relataram sobre populaçôes epifíticas de bactérias fitopatogênicas presentes em culturas exploradas economicamente, bem como em outros hospedeiros incluindo plantas daninhas.

Neste trabalho foram recuperadas colônias de $P_{s g}$ pelo método descrito em cafeeiros assintomáticos em todas as fases fenológicas estudadas, predominantemente da face inferior das folhas de cafeeiros. O meio de cultura semisseletivo utilizado permitiu identificar a presença da bactéria Pseudomonas syringae pv. garcae em plantas de cafeeiro assintomáticas.

Dentre os 27 isolados inicialmente selecionados devido às características morfológicas estarem associadas à $P s g$, todos foram gram negativos, sete demonstraram reação de hipersensibilidade em fumo positiva e Sudam negativo, seis destes tiveram reação de oxidase negativa e um deles positiva, ou seja, pode tratar-se da espécie Pseudomonas cichorii (Swingle) e a confirmação necessita de testes moleculares. O número de colônias quantificadas desta espécie bacteriana foi, aproximadamente, de 268 e se concentraram na face inferior da folha.

VolOudakis et al. (1991) recomenda que durante o estudo de população epifítica é necessário que se faça isolamentos e, posteriormente, análises laboratoriais para certificação do agente causal da doença, pois no caso de Pseudomonas syringae pv. tomato e $P$. $s$ pv. syringae a similaridade em relação aos sintomas é grande. McCARTER et al. (1983) relata que a detecção de baixos níveis populacionais de epífitas é limitada pela sensibilidade dos métodos de avaliação disponíveis. Esta necessidade de certificação deve ser confirmada mesmo para espécies que definem sintomas diferentes como é o caso de Psg e Pseudomonas cichorii.

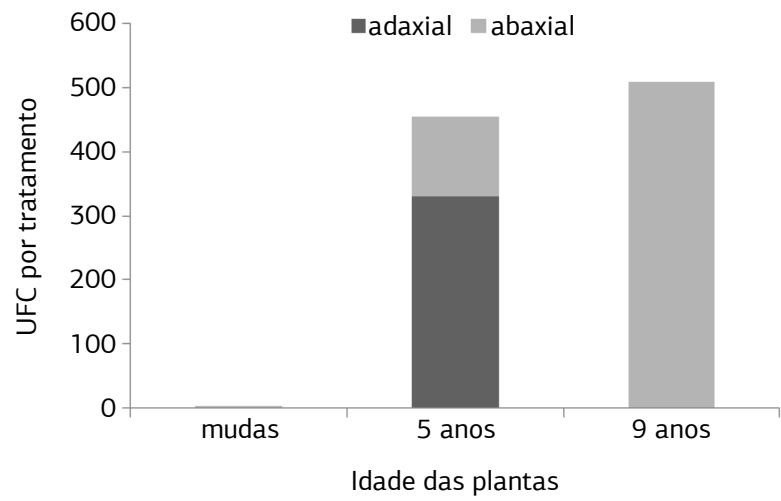

Figura 2. Unidades formadoras de colônia (UFC) de Pseudomonas syringae pv. garcae em folhas de plantas de cafeeiro assintomáticas coletadas no Município de Tiros (MG).
A pequena quantidade de colônias de Psg, recuperadas de mudas pode ser devido à aplicação recente de hipoclorito de sódio (puro ou água sanitária) (equivalente a 0,3 litros ha ${ }^{-1}$ ), prática que está sendo difundida nos municípios de Patos de Minas, Rio Paranaíba e Tiros. Possivelmente, deve ter ocorrido uma desinfecção superficial das folhas.

Evidências da disseminação da mancha aureolada através de mudas aparentemente sadias, mas hospedando a bactéria na forma epifítica foram observadas durante as visitas aos cafezais novos com menos de um ano muitos afetados com a mancha aureolada. As mudas para o plantio daqueles cafezais haviam sido adquiridas de viveiros que tinham eliminado previamente grandes quantidades de mudas com sintomas, mas as restantes aparentemente sadias haviam sido vendidas.

O método de detecção de $P s g$ descrito para identificar a presença da bactéria, associado à observaçáa das condiçóes climáticas favoráveis, permite realizar medidas de controle preventivas. Realizar o controle da época de poda para evitar brotaçóes novas nas épocas do ano cujas condiçôes climáticas estão mais favoráveis à doença, proteger as áreas de produção de mudas e aplicar fungicida à base de cobre podem evitar as perdas de produtividade pela morte dos ramos jovens devido a $P s g$.

Em relação aos sintomas em folhas novas não houve diferença significativa entre as variedades. Já com as folhas velhas, somente houve diferença entre Acaiá e Catuaí 99. Todas as cultivares testadas foram suscetíveis à mancha aureolada quando submetidas à inoculação e sob condições favoráveis à infecção (Tabela 3).

Em relação aos sintomas avaliados em folhas velhas, houve diferença estatística entre as variedades, sendo a cultivar Acaiá Cerrado a mais suscetível, mas não diferiu estatisticamente das demais, exceto Catuaí 99, que dentre as avaliadas foi a de menor severidade.

A idade fisiológica de órgãos vegetais influencia na severidade da doença. Devido às folhas novas terem estrutura mais tenra acaba por favorecer a penetraçáo do patógeno, constatando a observação empírica realizada por Oliveira e Romeiro (1990). Tal fato pode ser reafirmado observando-se a menor severidade nas folhas adultas em relação às médias em folhas jovens.

Tabela 3. Notas para a severidade da mancha aureolada em folhas novas e velhas de plantas de cafeeiros de diferentes variedades

\begin{tabular}{lll|} 
Variedades & \multicolumn{2}{c}{ Nolhas } \\
\cline { 2 - 3 } ACAIÁ & $4,22 \mathrm{a}^{*}$ & Velhas \\
CV 51 & $4,22 \mathrm{a}$ & $2,55 \mathrm{a}$ \\
\hline TOPÁZIO & $4,00 \mathrm{a}$ & $2,11 \mathrm{ab}$ \\
\hline MN & $3,89 \mathrm{a}$ & $2,22 \mathrm{ab}$ \\
\hline IAPAR & $3,78 \mathrm{a}$ & $2,22 \mathrm{ab}$ \\
\hline CATUAÍ 99 & $3,55 \mathrm{a}$ & $1,89 \mathrm{ab}$ \\
\hline
\end{tabular}

Médias seguidas por letras distintas, para cada tipo de folha, diferem entre si pelo teste de Tukey a $5 \%$ de probabilidade. 
Tabela 4. Crescimento de isolados de Pseudomonas syringae pv. garcae na presença de cobre coletados nas regiōes do Triângulo Mineiro e Alto Paranaíba

\begin{tabular}{lccccccc} 
& \multicolumn{9}{c}{ Concentração de cobre (ppm) } \\
\cline { 2 - 8 } Isolados & 0 & 50 & $\mathbf{1 0 0}$ & $\mathbf{2 0 0}$ & $\mathbf{3 0 0}$ & $\mathbf{5 0 0}$ & $\mathbf{1 0 0 0}$ \\
76 (Carmo do Paranaíba) & $(+)$ & $(+)$ & $(+)$ & $(-)$ & $(-)$ & $(-)$ & $(-)$ \\
95 (Patrocínio) & $(+)$ & $(+)$ & $(+)$ & $(-)$ & $(-)$ & $(-)$ & $(-)$ \\
97 (Patos de Minas) & $(+)$ & $(+)$ & $(+)$ & $(-)$ & $(-)$ & $(-)$ & $(-)$ \\
98 (Patrocínio) & $(+)$ & $(+)$ & $(+)$ & $(-)$ & $(-)$ & $(-)$ & $(-)$ \\
102 (Carmo do Paranaíba) & $(+)$ & $(+)$ & $(+)$ & $(-)$ & $(-)$ & $(-)$ & $(-)$ \\
\hline
\end{tabular}

(+) crescimento; (-) ausência de crescimento.

Como não foram encontrados relatos anteriores relacionados à seleção de materiais resistentes ou tolerantes a $P_{s g}$, é importante salientar a necessidade desta observância, pois este define um caminho mais eficiente para o controle de enfermidade, principalmente pela ausência de controle químico.

De acordo com a tabela 4, nos seis isolados testados ocorreu a mesma sensibilidade ao cobre, e a inibição iniciou-se a partir de $200 \mu \mathrm{g} \mathrm{mL} \mathrm{m}^{-1}$, o que parece ser um pequeno nível de resistência ao cobre. Segundo SiLva (1993), meios de crescimento não podem ser tratados como um sistema quimicamente inerte com funçấo única de suportar crescimento biológico. A possibilidade de ocorrer interaçôes adversas entre metais como o cobre e meio de cultura é muito alta e certamente este fator necessita ser levado em consideração. É possível que em meio de cultura o cobre esteja indisponível, o que pode levar a resultados inconclusivos. Nos tratamentos a $100 \mu \mathrm{g} \mathrm{mL}^{-1}$ de cobre foi observada alteraçáo nítida na coloração do meio como afirmado por Silva (1993).

\section{CONCLUSÃO}

A ocorrência de mancha aureolada é variável nas áreas de cultivo de café dos cerrados no Triângulo Mineiro e Alto Paranaíba. Nos municípios de Araguari, Romaria, Monte Carmelo, Coromandel e outros adjacentes, cujas lavouras estáo situadas abaixo de $950 \mathrm{~m}$ de altitude em relevo suave, a ocorrência da mancha aureolada é esporádica e limitada a poucas áreas, não sendo uma doença preocupante para os produtores. Nas áreas serranas, de topografia acidentada e altitudes mais elevadas, temperaturas amenas e sujeitas a ventos fortes ou contínuos, compreendendo os municípios que estendem de Patrocínio a São Gotardo, há ocorrência da doença todos os anos, com intensidade variada e imprevisível. Dentre as cultivares testadas não foi constatado nenhum material resistente à mancha aureolada.

\section{AGRADECIMENTOS}

À Embrapa/Café e ao CNPq pelo apoio financeiro de auxílio à pesquisa, fundamental para o desenvolvimento deste trabalho. Especialmente agradeço aos profissionais do Instituto de Ciências Agrárias, Laboratório de Fitopatologia (ICIAG/Lafip) da Universidade Federal de Uberlândia, local que permitiu desenvolver o presente trabalho, representada pelo pesquisador, orientador, Dr. Armando Takatsu. Como professor visitante na citada instituição, concedeu-me o privilégio de sua atenção por seis anos, em forma de conhecimentos cuidadosamente transmitidos, que compóem o sólido suporte da minha formação profissional, e permanecerão por toda a caminhada. Sinceramente agradeço ao pesquisador Dr. Carlos H. Uesugi por também compartilhar sua experiência e conhecimento nessa etapa valiosa, sem a qual não teria sido possível a conclusão deste trabalho.

\section{REFERÊNCIAS}

AMARAL, J.F.; TEIXEIRA, C.; PINHEIRO, E.D. O bactério causador da mancha aureolada do cafeeiro. Arquivos do Instituto Biológico, v.23, p.151-155, 1956.

ARAUJO, J.S.P.; ROBBS, C.F.; RIBEIRO, R.L.D. Manejo integrado de fitobactérioses de importância econômica no Brasil. Parte I. Revisão Anual de Patologia de Plantas, v.11, p.107-131, 2003.

CARVALHO, V.L.; CHALFOUN, S.M. Doenças do cafeeiro: diagnose e controle. Belo Horizonte: Empresa de Pesquisa Agropecuária de Minas Gerais, 2000. 44p. (Boletim Técnico, 58)

GODOY, C.V.; BERGAMIN FILHO, A.; SALGADO, C.L. Doenças do cafeeiro. In: KIMATI, A.; AMORIM, L.; BERGAMIN FILHO, A.; CAMARGO, L.E.A.; REZENDE, J.A.M. Manual de Fitopatologia. 3.ed. São Paulo: Agronômica Ceres, 1997. v.2, p.184-206.

FERREIRA, L.P.; SALGADO, C.L. Bactérias. In: BERGAMIN, A.F.; KIMATI, H.; AMORIN, L. Manual de Fitopatologia: doenças das plantas cultivadas. São Paulo: Ceres, 1997. v.2, p.184-200.

HIRANO, S.S.; UPPER, C.D. Ecology and epidemiology of foliar bacterial plant pathogens. Annual Review of Phytopathology, v.21, p.243-269, 1983.

JESUS JUNIOR, W.C.J.; ZAMBOLIM, L.; SILVA, H.S.; VALE, F.X.R.; SILVA, C.L. Controle químico da mancha aureolada do cafeeiro. Fitopatologia Brasileira, v.27, p.61, 2002. (Suplemento)

KADO, C.E; HESKETT, M.G. Selective media for isolation of Agrobacterium, Corynebacterium, Erwinia, Pseudomonas and Xanthomonas. Phytopathology, v.60, p.969-976, 1970.

KING, E.O.; WARD, M.K.; RANEY, D.E. Two simple media for the demonstration of pyocuanin and fluorescein. Journal of Laboratory and Clinical Medicine, v.44, p.301-307, 1954.

McCARTER, S.M.; JONES, J.B.; GITAITIS, R.D.; SMITLEY, D.R. Survival of Pseudomonas syringae pv. tomato in association with tomato seed, soil, host tissue, and epiphytic weed host in Georgia. Phytopathology, v.73, p.1393-1398, 1983. 
OLIVEIRA, J.R.; ROMEIRO, R.S. Reação de folhas novas e velhas de cafeeiros a infecção por Pseudomonas cichorii e $P$. syringae pv. garcae. Fitopatologia Brasileira, v.15, p.355-356, 1990.

PATRÍCIO, F.R.A.; ALMEIDA, I.M.G.; BARROS, B.C.; SANTOS, A.S. Effect of fungicides, antibiotics, and acibenzolar-Smethyl over cercosporiosis and bacterial halo blight in coffee plants. Fitopatologia Brasileira, v.27, p.147, 2002. (Suplemento)

SERA, T. Coffee genetic breeding at IAPAR. Crop Breeding and Applied Biotechnology, v.1, p.179-190, 2001.

SILVA, V.L.; LOPES, C.A. Populaçóes epifíticas de Pseudomonas syringae pv. tomato em cultivo comercial de tomateiro industrial. Fitopatologia Brasileira, v.20, p.179-183, 1995.

VALE, F.X.R. ; ZAMBOLIM, L. . Controle de doenças de plantas: grandes culturas. 1.ed. Visconde do Rio Branco, MG: Suprema, 1997. v.2, 1132p.
VOLOUDAKIS, A.E.; GITAITIS, R.D.; WESTBROOK, J.K.; PHATAK, S.C.; McCARTES, S.M. Epiphytic survival of Pseudomonas syringae pv. syringae and $P$. s. tomato on transplants in Southerm Georgia. Plant Disease, v.75, p.672-675, 1991.

YOUNG,J.M.;DYE,D.W.;BRADBURY,J.F.;PANAGOPOULOS, C.G.; ROBBS, C.F. A proposal nomenclature and classification for plant pathogenic bacteria. New Zealand Journal of Agricultural Research, v.21, p.153-177, 1978.

ZAMBOLIM, L.; VALE, F.X.R; PEREIRA, A.A.; CHAVES, G.M. Manejo Integrado das Doenças do Cafeeiro. In: ZAMBOLIM, L. Encontro sobre produçáo de café com qualidade, 1., 1999. Viçosa. Palestras... Viçosa: Universidade Federal de Viçosa, 1999. p.134- 215.

ZAMBOLIM, L.; VALE, F.X.R.; ZAMBOLIM, E.M. Doenças do Cafeeiro. In: KIMATI, A.; AMORIM, L.; REZENDE, J.A.M.; BERGAMINFILHO,A.; CAMARGO,L.E.A. Manual deFitopatologia. 4.ed. São Paulo: Agronômica Ceres, 2005. v.2, p.165-180. 